\title{
Stay at Home Reservation: The Mitigation Step in Covid-19 Pandemic
}

\author{
Faridiah Aghadiati Fajri ${ }^{1}$, Muhammad Fakhrurrifqi ${ }^{2}$, Dian Budi Santoso ${ }^{3}$, Radhian Krisnaputra ${ }^{4}$ \\ ${ }^{1}$ Public Sector Accounting, Vocational College, Universitas Gadjah Mada, Yogyakarta, Indonesia \\ ${ }^{1}$ faridiahagha@ugm.ac.id \\ ${ }^{2}$ Electrical Engineering and Informatics, Vocational College, Universitas Gadjah Mada, Yogyakarta, Indonesia \\ ${ }^{3}$ Health Information Management, Vocational College, Universitas Gadjah Mada, Yogyakarta, Indonesia \\ ${ }^{4}$ Mechanical Engineering Technology, Vocational College, Universitas Gadjah Mada, Yogyakarta, Indonesia
}

\author{
Accepted on November 22, 2020 \\ Approved on June 02, 2021
}

\begin{abstract}
The Covid-19 pandemic condition that has hit the world has had a significant impact on various sectors. Health facilities need information system support in their services. Breaking the distribution chain can be done by maintaining a physical distance. However, in reality, people are still indifferent. There is a possibility that the patient is infected but shows no symptoms or is lying to the point of endangering medical personnel. In addition, there is a stigma in the community so that they are afraid to go to health facilities. Even though it cannot be denied that in certain conditions patients should still have their conditions checked by a doctor. The development of this online registration system aims to reduce the risk of contact between patients and medical personnel. The real-time queue monitoring feature helps patients to wait in line anywhere, so they are not in the patient's waiting room. This system is able to provide real-time queues for examinations in all polyclinics. This can reduce public anxiety about coming to health facilities.
\end{abstract}

Index Terms-Covid-19; health facilities; online reservation; pandemic; realtime queues

\section{INTRODUCTION}

Coronavirus or COVID-19 is a contagious disease caused by severe acute respiratory syndrome coronavirus 2 or SARS-CoV-2 [1]. This virus was first identified in Wuhan, China in December 2019. Based on a report from the World Health Organization (WHO) states that the risk assessment at the global level for this pandemic is very high. This virus pandemic has affected almost all countries with a total of 2,078,605 confirmed cases as of April 17, 2020, with 139,515 deaths [2]. In Indonesia, the first case was identified on 2 March 2020 [3]. Since then cases have continued to increase until April 17, 2020, reaching 5,923 confirmed positive cases [4].

The government has done many ways to break the chain of spread and mitigate the effects of this pandemic. One of the policies chosen is social restrictions or social distancing. The implementation of social distancing began in mid-March 2020. Since then, the government has urged its citizens to worship, work, and learn from home. Social distancing is a nonmedical action taken to prevent the spread of infectious diseases by keeping a distance. This method is done to minimize the transmission of viruses that cause infectious diseases [5]. Reducing the number of people in a location, regulating queuing spacing, giving the distance in waiting chairs, canceling the agenda for activities that involve many people are steps in limiting distance. Kerkhove [6] prefers to use the phrase physical distancing rather than social distancing because these two things are different. The spread of infection is prevented by limiting physical contact not social contact. Currently, technology has supported the existence of adequate social activities or relationships without having to make physical contact.

In the context of tackling the COVID-19 pandemic, health workers continue to work as closely as possible. The use of Personal Protective Equipment (PPE) is maximized to prevent transmission. This social restriction has an impact on the number of people returning to their hometowns from the Red Zone area. This raises obstacles faced by health workers in the regions. The results of an interview in April with one of the medical personnel at Puskesmas Kulati, Tomia Island, Southeast Sulawesi, until now they have not received logistics either in the form of PPE or vitamin supplements. Health workers who are members of the Ministry of Health's program are raising donations for the procurement of PPE. The logistical distribution process that has not yet touched remote areas can be due to several factors, such as limited PPE so that the distribution process is prioritized for zones that are more in need or the unavailability of an integrated information system infrastructure regarding data collection from health centers in Indonesia.

In April, there were cases of 46 medical personnel at the Rumah Sakit Umum Pemerintah (RSUP) dr. Kariadi, Semarang which contracted the COVID-19 virus [7]. Transmission of the Covid-19 virus to medical personnel can be infected from the hospital environment and from outside the hospital. However, 
the chances of these medical personnel being infected when they are treating patients. The possibility of a patient who is dishonest at the time of initial screening in the examination procedure increases the risk of medical personnel being exposed to infection so that more optimal screening tools are needed. Several hospitals have developed an information system for this screening but the puskesmas do not yet have an adequate system so that screening is carried out manually by interview. This could endanger medical personnel who are very limited in the area.

In rural areas, puskesmas are at the forefront of public health services. Local health centers have many limitations, making it impossible to handle infected patients. If a patient is infected, the nearest referral hospital is needed. Information as of April 15, 2020, there were 800 referral hospitals and locations for Covid-19 testing [8]. The large number of people moving from cities to regions carries a bad possibility, so an information system that can be updated at any time is needed as a means of information for subscribing to COVID-19 patients. In addition, the screening process with various scenarios is designed so that medical personnel do not have direct contact with infected patients because there is a trend that infected patients do not show symptoms of the corona.

Patient registration at the First Level Health Facility or Fasilitas Kesehatan Tingkat Pertama (FKTP) is still done manually, patients come to register. Furthermore, the patient immediately waits in the patient's waiting room for medical services. In this registration process, there is contact between the patient and the administrative staff at the Puskesmas or Clinic. When a patient is in the waiting room before getting service, it is possible to have contact with other patients even though health protocols have been carried out, such as wearing a mask, maintaining distance, and washing hands. This risk can be minimized by developing an online queue registration and review information system. The development of this system is expected to be used by puskesmas and health facilities in Indonesia.

Apart from aiming to mitigate a pandemic, the design of this system is different from most systems in Puskesmas. This web-based application development aims to make it easier for users so that they do not need to download and install applications. Web-based systems are seen as more user-friendly with all devices that the user has. There is an online queue feature which is the second answer to the need for new normal conditions to deal with this pandemic. The real-time online queue monitoring feature allows users to monitor queue numbers anywhere. Patients do not have to be in a health care center so that it can reduce the risk of transmission in health facilities.

\section{RESEARCH METHOD}

The development of this information system can be used by puskesmas in Indonesia to provide accurate and real-time data to patients regarding doctor's examination schedules and polyclinic queues. The existence of an initial screening feature in the online registration process can contact patients with infections. This early screening feature can also be used by the community to carry out early detection. The socialization of the use of the online registration system was carried out using a media banner in front of the Puskesmas registration counter.

The development of this application uses an agile software development methodology. The Covid-19 pandemic has made the situation very dynamic. This method is able to accommodate application development in dynamic and unpredictable environments [9]. This method is a short-term system development which is a rapid adaptation of the developer for changes. The choice of this method is expected to be able to cut system development time so that applications can be immediately used to mitigate conditions due to the Covid-19 outbreak.

System analysis was conducted to obtain information about the patient registration cycle that has been carried out so far. This process analyzes what data is needed in the cycle. This analysis is followed by designing a new system. This design produces the necessary diagrams, namely Context Diagrams, Data Flow Diagrams (DFD), User Diagrams, and Entity Relationship Diagrams (ERD). In addition, the design is also equipped with a Data Dictionary, Menu Structure, File Structure, and input and output design. This initial process requires systematic steps so that the application is made according to the needs. The system analysis process also focuses on user requirements, both functional requirements, and nonfunctional requirements. This user-focused system development uses a Software Process Improvement (SPI) framework which is expected to increase the success of implementing information systems.

Software development is costly. Software Process Improvement (SPI) is the main strategy used by software developers to reduce development costs or to increase production speed and quality. SPI is closely related to user, environmental, social, and organizational factors. The motivation for all related elements must be managed properly so that SPI can run optimally [10], [11].

Goldenson, et al. [12] conducted a survey on software process improvement to understand how its benefits and what factors affect the SPI process. Factors associated with a successful SPI effort include:

1. Employees in organizations involved in SPI are respected employees or hold important positions so that other staffs involved are willing to work better together. 
2. Technical staffs are more involved in the SPI process, starting from mapping conditions because technical staffs are the ones who best understand the information technology needs of their organization.

3. The management of staff resources and working time has been re-managed when the staff is asked to be involved in SPI activities so that the staff does not feel that they are getting additional work without compensation for their daily work.

4. The objectives of carrying out SPI and their objectives have been well explained and understood within the organization, especially for those who are directly involved in the process as well as for its users.

The process begins with the determination of goals. Then a measurement feasibility analysis is carried out so that it can be measured whether the development process is feasible, if not, it will be returned to the initial goal determination [13]. Software Process Improvement (SPI) is a series of activities that go through several stages and involve many parties. Support from personnel in the organization plays an important role so that the objectives, implementation schedule, and division of work must be well understood.

The next stage is the database design and interface design. The context diagram in Fig. 1 shows the system's interactions with external entities, namely admins, patients, doctors, and service staff.

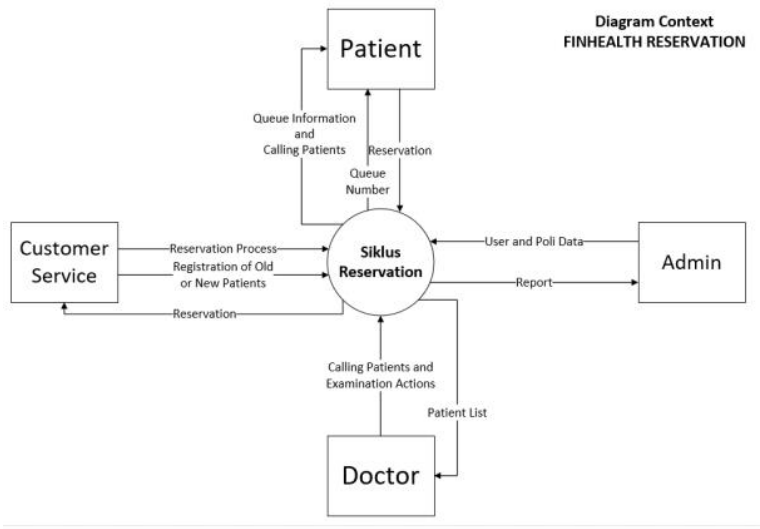

Fig. 1. Context diagram

Admin has full rights over the system and data management. The patient in the diagram has the authority to manage his profile. Doctors in this system have limited rights to the patient list on the reservation, while service staff can make on-site reservations and register patient data. The next diagram is a Level 0 Data Flow Diagram (DFD) which shows the subsystem of this reservation application.

Fig. 2 shows the login process by patients, doctors, admins, and service staff. The next process is to find the appropriate poly and schedule for the patient. Patients make reservations and enter the poly queue according to the selected health service schedule.

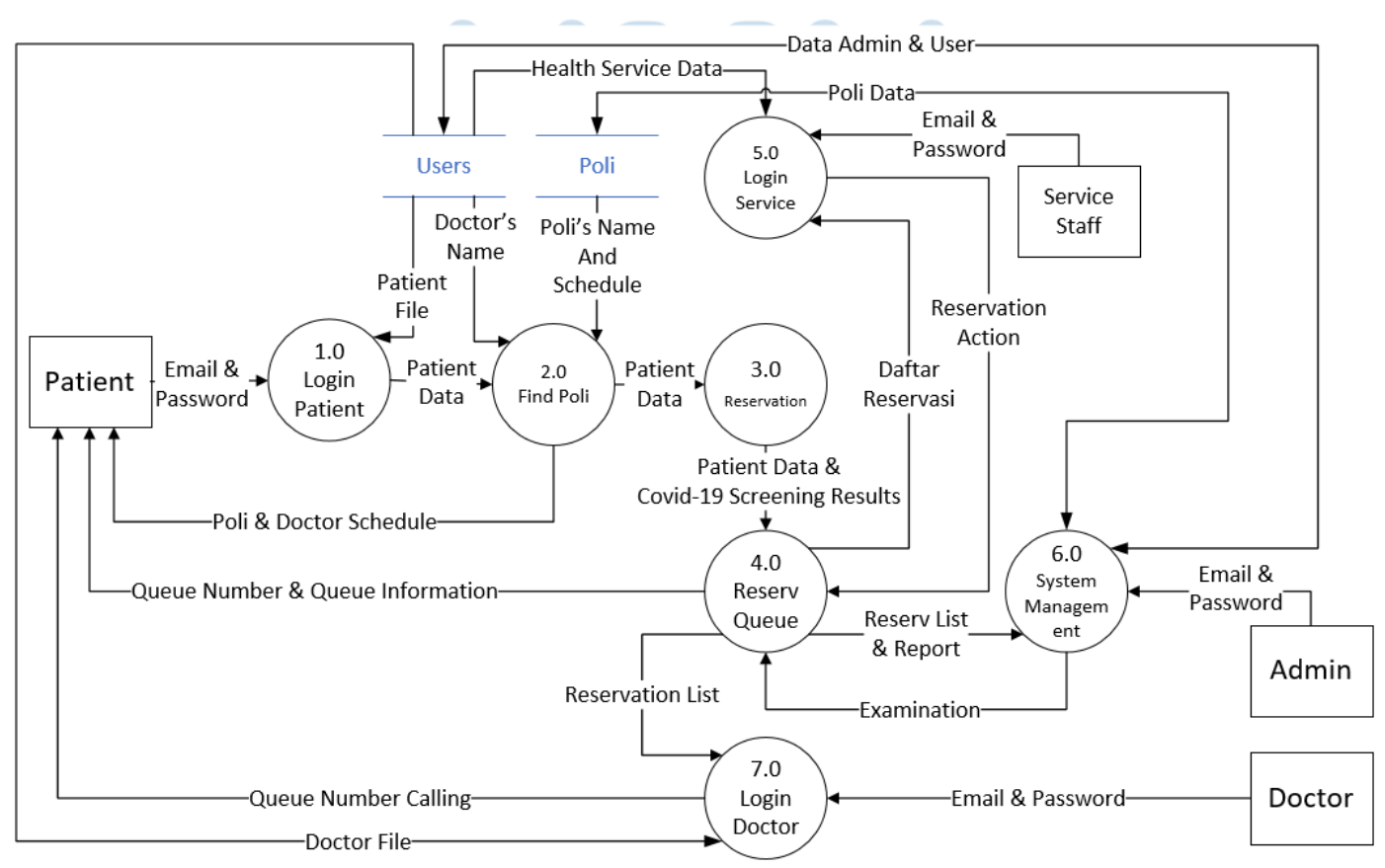

Fig. 2. DFD level 0 
DFD level 0 shows the process in detail. Patients are described as being able to make profile changes, make schedule selections, and submit medical service reservations. Doctors only have limited authority, which is to see the queue list on the police and call patients according to the order. Service staff can help patients who have not used this application to register on the spot. In addition, service staff can add new patient data, manage old patient data, and change the status of patients in the queue.

Fig. 3 shows that the admin can manage patient, doctor, schedule, and poly data and can generate reports. Admin enters the email address and password to enter the system. After entering the system, the admin can see the polyclinic schedule. If there is a new poly schedule or doctor's schedule change, the admin can manage it through the schedule management feature. The admin can get queue data from all the reservations carried out in all polyclinics. In this system, the admin will create a report that shows the number of patient registrations that were carried out, cancellation of health services, and the results of Covid-19 screening.

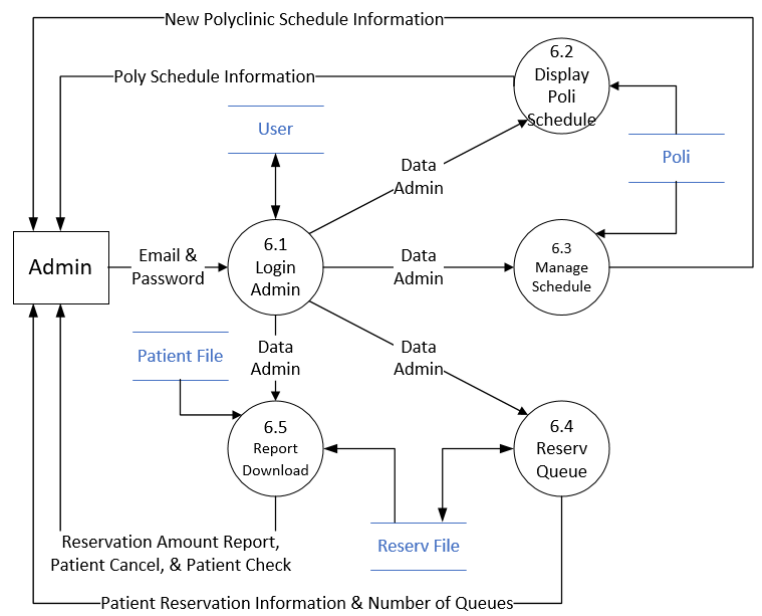

Fig. 3. Context diagram
An entity-relationship diagram is a form of arrangement of tables in a database, including relations between one table with another table. This model that combines some semantic information is introduced as a tool for database design. Also, the entity relational model can be used as the basis for unifying various data views: the network model, the relational model, and the entity-set model [14]. The theory of normalization is easy to understand, but in practice, small-scale application developers do not use this theory in database implementation on their systems. One of the causes is a lack of understanding of the normalization process. Arini, et al. [15] found that ERD becomes a bridge that simplifies the database normalization verification process because it can be seen the representation of the same number of entities in the ERD with the number of tables in the database schema.

Cagiltay, et al. [16] found that detecting defects in the types of missing information in ERD was more difficult than detecting other types of defects. ERD designs are used to better represent information and to minimize development errors for these designs, which in turn lowers the cost of the software project. This software was developed using data correspondence with the Kulonprogo Health Office. This project employs 2 Health center or Pusat Kesehatan Masyarakat (PUSKESMAS), namely Puskesmas Panjatan I and Puskesmas Panjatan II as locations for User Acceptance Test (UAT).

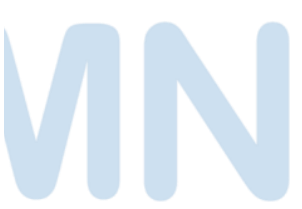




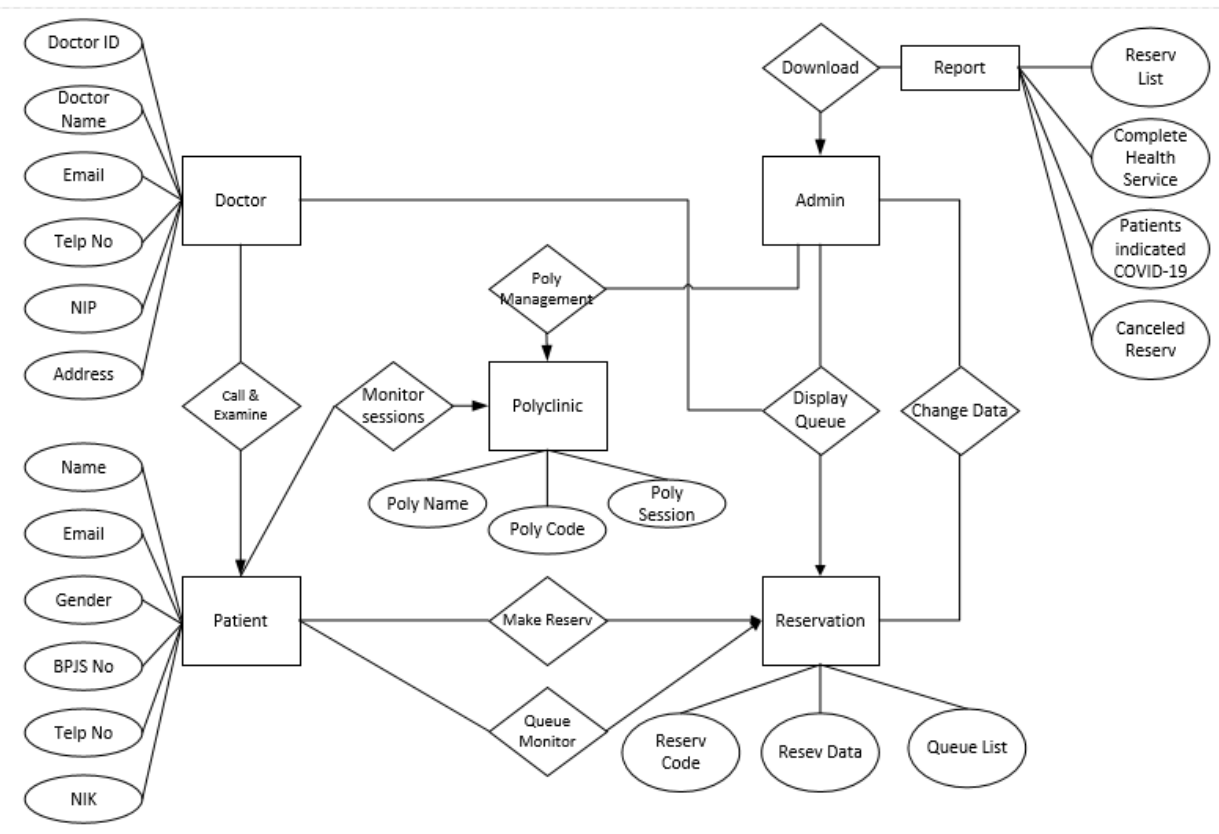

Fig. 4. Entity relational diagram

\section{FINDING AND DISCUSSION}

This application can be operated using personal computers, laptops, and other smart devices connected to the internet. Users can use any web browser. Users can start using it by entering the address of each health facility according to the area. Based on the design in the previous chapter, this system has been successfully developed and has been registered with the Ministry of Law and Human Rights, Directorate General of Intellectual Property with registration number 000195166. Fig. 5 shows the initial view of the user. The login menu is used to enter the application using an email address and password while the register menu is used to enroll a new account. Users can immediately make a reservation by clicking the Reservation button. The last button on this display functions to monitor the queue in real-time.

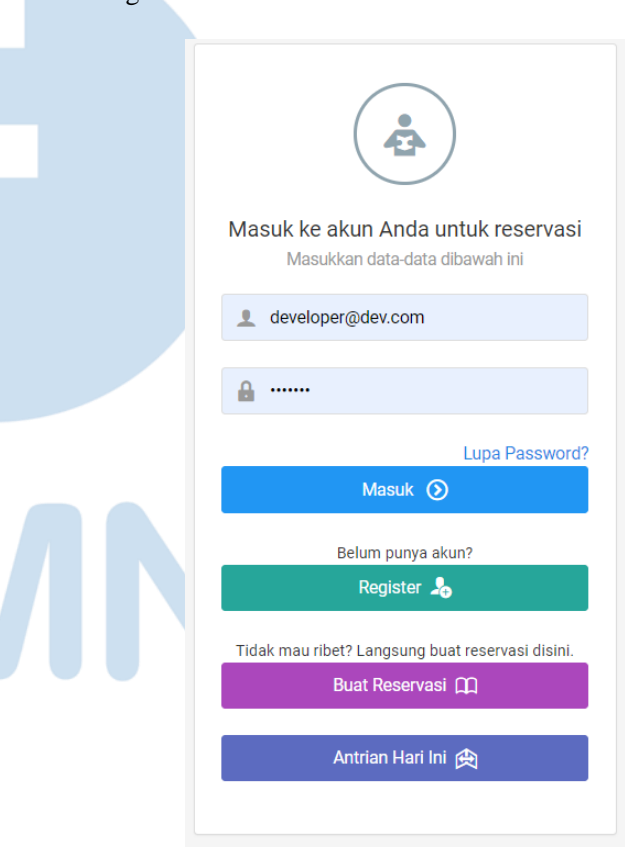

Fig. 5. Welcome page

The following are examples of the displays from the submenu in the application. Fig. 6 shows the instant reservation menu display. Patients are asked to enter their name, telephone number, NIK, Health Insurance Number, and choose the poly they will go to. The picture shows a number of polys which are owned by the health center. This policy can be adjusted by each user according to their conditions.

As a follow-up step, the developer can consolidate with the local Communication and Informatics Office of the District to be able to create a domain for each Puskesmas. The database can be drawn from the Department of Population and Civil Registration data, 
although the home base of the patient is still adjusted to the area of residence.

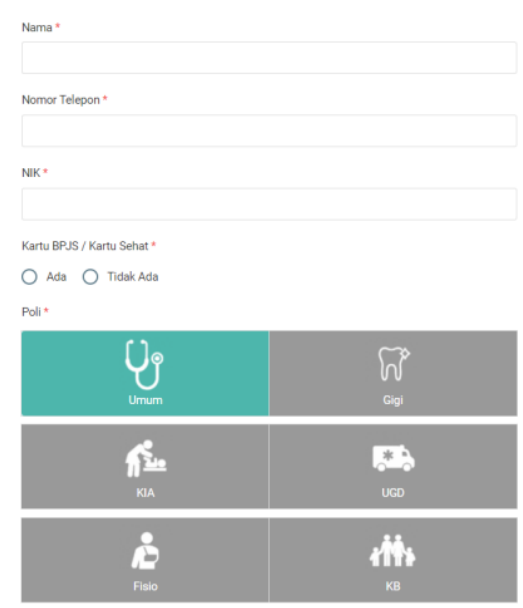

Fig. 6. Reservation menu

In the admin menu, there is full control over this application. Admin can make changes to data both patient data, doctor, schedule, to poly. The admin is in charge of managing the doctor's practice time and the length of service for each patient. Admins also get access to reports that can be generated by this application. Some of the existing reports include patient registration reports, dependent patients, patients who canceled treatment, and patients who are indicated by Covid-19. Based on this report, health facilities can make various decisions in order to manage their health facilities in the midst of this pandemic.

Doctors have a limited menu on this application in the hope that this application does not add to the workload. The doctor only presses the patient's call button according to the order in the application. The doctor can monitor the number of patients enrolled in each session. While the service staff is tasked with backing up patients who have not used this application to register. Service staff can add new patient profiles, modify patient data, and make reservations. During this service, the staff urges patients to monitor the queue via the application site and come after their turn so there is no need to stay in the patient waiting room.

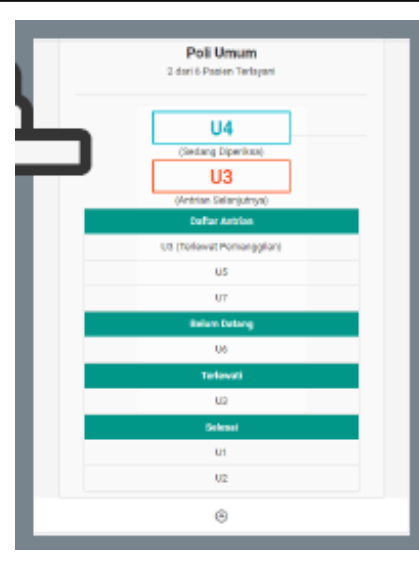

Fig. 7. Real-time queue

The target users of this application are puskesmas patients who live in the working area of the puskesmas. Fig. 7 shows the queue number being checked by the doctor and the next queue number that will be called immediately. At the bottom, there is a list of registration numbers so that patients can monitor where the queue is. Furthermore, there is information on patients who were missed or did not come when called and a list of patients who had received health services. This real-time queuing feature is expected to be fully utilized in the current pandemic conditions. Using this feature allows patients to wait at home until the queue is nearby.

\section{CONCLUSION AND FUTURE WORKS}

This pandemic is an extraordinary condition that must be faced together. Health workers struggle to cure infected patients. As good citizens, we must also be able to look after Indonesian medical personnel by implementing health protocols. In addition, the use of this online registration system also provides various benefits for both patients and health workers. The use of this system can reduce contact between patients and patients with health staff so that it is expected to play a role in mitigating the various impacts of the Covid-19 pandemic.

This research has a practical impact, health facilities throughout Indonesia can use the concepts and designs that have been described to develop similar applications. This system can be developed on a large scale so that it can reduce the level of transmission of pandemics and other diseases. This study has several limitations. First, the results of the development and application of this software cannot be measured with exact numbers because the number of patients exposed until this paper was written could not be controlled. However, it is hoped that the development of this system can be one of the factors capable of mitigating the current transmission of Covid-19 and the transmission of other infectious diseases in conditions after the Covid-19 pandemic ends. Further research can measure the level of success of this information system by comparing the 
level of effectiveness and efficiency of business processes in health facilities. Second, this software is designed in Indonesian with the hope that it will be easier for users to understand, namely people in rural areas who still have difficulty accessing health services to hospitals. Further research can develop other applications that can use English if indeed the target user uses English as their daily language.

\section{REFERENCES}

[1] WHO, "Naming The Coronavirus Disease ( COVID-19 ) and The Virus That Causes It," World Health Organization, 2020.

[2] WHOReport, "Coronavirus disease 2019 (COVID-19): Situation Report - 76," 2020.

[3] R. S. Nugroho, "Rekap Kasus Corona Indonesia Selama Maret dan Prediksi di Bulan April,” Kompas, pp. 1-17, 2020.

[4] Kawalcovid19.id, "Kawal informasi seputar COVID-19 secara tepat dan akurat," 2020.

[5] WHO, "Social Distancing," World Health Organization, 2020.

[6] M. Van Kerkhove, "Emergencies Coronavirus Press Conference," 2020. [Online]. Available: https://www.who.int/docs/defaultsource/coronaviruse/transcripts/who-audio-emergenciescoronavirus-press-conference-full20mar2020.pdf?sfvrsn=1eafbff_0.

[7] CNN, "RSUP dr Kariadi Selidiki Kasus 46 Medis Tertular Covid- 19," 2020 .

[8] Kompas, "Update 15 April: 5.136 Kasus Positif Covid-19,
800 RS Rujukan Dioperasikan, hingga Produksi 16.000 APD," 2020.

[9] J. A. Highsmith and J. Highsmith, Agile Software Development Ecosystems. 2002.

[10] N. Baddoo and T. Hall, "De-motivators for Software Process Improvement: An Analysis of Practitioners' Views," J. Syst. Softw., vol. 66, pp. 23-33, 2003, doi: 10.1016/S01641212(02)00060-2.

[11] I. E. Espinosa-curiel and J. Rodríguez-jacobo, "Understanding SPI in Small Organizations: A Study of Mexican Software Enterprises," J. Softw. Evol. Process, no. April, pp. 372-390, 2016, doi: 10.1002/smr.

[12] D. R. Goldenson, J. D. Herbsleb, D. R. Goldenson, and J. D. Herbsleb, "After the Apraisal: A Systematic Survey of Process Improvement, Its Benefits, and Factors that Influence Success," Pittsburgh, Pennsylvania, 1995.

[13] S. Bibi, I. Stamelos, G. Gerolimos, and V. Kollias, "BBN Based Approach for Improving The Software Development Process of An SME - A Case Study," J. Softw. Maint. Evol. Res. Pract., vol. 22, no. May 2009, pp. 121-140, 2010, doi: 10.1002/spip.

[14] P. Chen Pin-shan, "The Entity-Relationship Unified View of Data Model-Toward a," ACM Trans. Database Syst., vol. 1, no. 1, pp. 9-36, 1976.

[15] F. Y. Arini, R. Arifudin, and M. Aris, "Applied structured database in a small project," J. Phys. Conf. Ser., vol. 1321, no. 3, 2019, doi: 10.1088/1742-6596/1321/3/032130.

[16] N. E. Cagiltay, G. Tokdemir, O. Kilic, and D. Topalli, "Performing and analyzing non-formal inspections of entity relationship diagram (ERD)," J. Syst. Softw., vol. 86, no. 8, pp. 2184-2195, 2013, doi: 10.1016/j.jss.2013.03.106. 